\title{
On Writing Sculptural Hypertext
}

\author{
Mark Bernstein \\ Eastgate Systems Inc, USA \\ National University of Singapore \\ E-mail: bernstein@eastgate.com
}

\author{
David E. Millard \\ Intelligence, Agents, Multimedia Group \\ University of Southampton, UK \\ E-mail: \{dem, mjw \}@ecs.soton.ac.uk
}

\begin{abstract}
Sculptural hypertext is proposed as an alternative domain for hypertext writing, proceeding chiefly by the removal of links rather than by adding links to an initially unlinked text. Relatively little is known about authoring sculptural hypertexts. This paper examines some issues that arise in the course of composing sculptural hypertexts and proposes tools which might help support such designs.
\end{abstract}

\section{Categories and Subject Descriptors \\ H.5.4 [Hypertext/Hypermedia]: Theory.}

\section{General Terms}

Design, Experimentation, Theory.

\section{Keywords}

Sculptural Hypertext, Authoring, Hypermedia Structure, Context, Narrative

\section{INTRODUCTION}

Conventional hypertexts are constructed by adding links to initially unlinked nodes until the desired connections are created; we term these "calligraphic". Sculptural hypertexts $[1,12]$ begin with nodes that are, initially, completely connected; the writer removes links until only the desired connections remain. ("Calligraphic" is used here in its art-historical sense, distinguishing drawing from tonal forms, rather than its colloquial reference to fancy handwriting)

Card Shark applies a concrete metaphor of playing a sequence of cards from a hand to the reading of a hypertext. The reader is dealt a set of cards, and may then select the card to read selecting a card is, in effect, traversing a link. Each card includes constraints, which may restrict the context in which the card may be read, and assertions that modify the reading context. The context thus constrains which cards may be read at a given point, permitting the author to establish causal relations and temporal coherence. The reading continues until no more cards remained

Permission to make digital or hard copies of all or part of this work for personal or classroom use is granted without fee provided that copies are not made or distributed for profit or commercial advantage and that copies bear this notice and the full citation on the first page. To copy otherwise, or republish, to post on servers or to redistribute to lists, requires prior specific permission and/or a fee.

Conference '00, Month 1-2, 2000, City, State.

Copyright 2000 ACM 1-58113-000-0/00/0000 ..\$5.00. playable.

In a similar way, the Story Engine client constructed on top of the Auld Linky structural link server [9] allows a reader to choose from a number of links to story fragments. Whether a link is available depends on the current reading context (as opposed to the current story fragment). Behaviors on the links modify the reading context when links are followed.

How does writing a sculptural hypertext differ from more traditional hypertext systems? What tools might hypertext sculptors require?

\section{CONTEXT}

In a sculptural hypertext, the context determines which cards can be read immediately, and which must be deferred or omitted entirely. As the reading progresses, the context constrains the choice of cards, and the chosen cards in turn change the context. Effective writing often hinges on skillful use of context; merely choosing nodes at random seems an unpromising rhetorical strategy. (Note, however, that early sculptural hypertexts like its name was Penelope [7] and Forward Anywhere [8] rely on random juxtaposition to a remarkable degree [5]).

It is tempting to explore a rich taxonomy of sculptural contexts elements, in which temporal constraints, causal relationships, psychological contingencies and user models might all play a role. Interactive fiction tools that attempt to construct detailed world models have thus far proven disappointing, in part because the combination of world models and the widespread assumption that the reader should enact the protagonist's role is fundamentally incoherent [1]: the Holodeck cannot contain Hamlet (but see [10]).

We note, too, that the corresponding taxonomy of calligraphic link types has proven elusive [11]. Instead, we will explore three general families of context, examining their narrative role and the types of information they might contain:

Episodic - Scoping the story fragments to define episodes, control pacing, and generate narrative direction.

Time and space naturally lend themselves to episodic boundaries. A narrator, recounting stories of her childhood, might wander through the years dwelling now on a teenage romantic crisis and later on a kindergarten morning. In spatial narratives like Myst, progress through the hypertext entails motion through a fictional space [6]. 
Coherence Maintaining the local and global continuity of the story, avoiding internal contradictions and violations of causality.

Context makes it easy to avoid contradictions. If it's raining, a character can't talk about the fine weather. If (in one telling of a story) a character is glum, the character cannot inexplicably turn cheerful; we might allow that the character's mood might change in different retellings of the episode, or from one time to another, but mood should not change chimerically.

Episodic context can maintain continuity. Time and location can be used to ensure that the text does not accidentally contradict itself and that it retains focus on the topic at hand while remaining open to transitions to new episodes. Contextual transitions in time and space may be required to foreshadow events, or to recall events already described.

Craft and Construction Maintaining consistent rhetorical style, presentation, and voice.

Although one motivation for sculptural hypertext was its affinity for episodic coherence, it also offers opportunities to think about narrative craft. Early thinking about calligraphic hypertext sometimes focused on using links to direct the plot, and progress waited upon Bolter and Joyce's realization that much more could be done by using links to move across time, space, and point of view [3]. Context objects, to be sure, help maintain consistency and causality, but writers can use them to great effect in directing how the story unfolds.

Narrative propels itself toward resolution; we long to know who will triumph and who will fail, who will win the hero's heart (and how), who will be happy (and why). Yet the impact of the story requires space and time, time for the tale to unfold in its complexities and space for the characters to fill. Given too much space, the story loses impetus and becomes mere accretion of detail; given too little, the story rushes to its conclusion without the scope or energy to move us.

Context lets the writer direct not only what happens, but also how we are told. We might, for example, wish to provide multiple accounts of a single incident because:

- Contextual changes might prevent us from hearing one account. For example, if a character leaves a scene without relating the incident, another character might describe it later.

- Different moods or styles may require distinct accounts. If a scene might be realistic, but might under other circumstances become fantastic or wryly ironic, an account that fits one mood might prove off-key for another.

- Accounts that reflect different perspectives may themselves be of inherent interest. This is the Rashomon pattern [2].

Over time, the reader's choices give us intriguing information about their interests and desires. Constructing a user model from these hints is difficult [4], but speculations may prove rewarding correct while causing little harm if they prove wrong.

Finally, we may use context for matters of craft, outside the frame of the story. If a character has reached the end of the role in a scene, it is usually best to move the character off stage lest their forgotten presence later cause confusion.

\section{TOOLS FOR AUTHORING}

If we wish to see authors experiment with sculptural writing then we need to ease them into the process. We are currently exploring tools for:

- Using spatial triage to organize episodic contexts

- Allowing authors to view cards according to their assertions and/or constraints (to help manage coherence)

- Generating possibility trees to reveal probable trajectories and identify bottlenecks and unreachable states.

\section{ACKNOWLEDGMENTS}

This research is funded in part by EPSRC IRC project "EQUATOR" GR/N15986/01.

\section{REFERENCES}

1. Bernstein, M., Card Shark and Thespis: exotic tools for hypertext narrative. in Hypertext 2001: Proceedings of the 12th ACM Conference on Hypertext and Hypermedia, (Århus, Denmark, 2001), ACM, 41-50.

2. Bernstein, M., Patterns of Hypertext. in Hypertext '98, (Pittsburgh, PA, 1998), ACM, 21-29.

3. Bolter, J.D. and Joyce, M., Hypertext and Creative Writing. in Hypertext '87, (Chapel Hill, 1987), ACM, 41-50.

4. Brusilovsky, P., Stock, O. and Strapparava, C. Adaptive hypermedia and adaptive Web-based systems : international conference, $\mathrm{AH}$ 2000, Trento, Italy, August 28-30, 2000 : proceedings. Springer, Berlin; New York, 2000.

5. Golovchinsky, G. and Marshall, C.C., Hypertext Interaction Revisited. in Hypertext 2000, (San Antonio, Texas, 2000), ACM, 171-180.

6. Jenkins, H. and Fully, M. "Nintendo and New World Narrative". in Jones, S. ed. Communications in Cyberspace, Sage, Los Angeles, 1994.

7. Malloy, J. its name was Penelope, Eastgate Systems, Inc., Watertown, Massachusetts, 1993

8. Malloy, J. and Marshall, C. Forward Anywhere, Eastgate Systems, Inc., Watertown, Massachusetts, 1996.

9. Michaelides, D.T., Millard, D.E., Weal, M.J. and De Roure, D.C., Auld Leaky: A Contextual Open Hypermedia Link Server. in Proceedings of the 7th Workshop on Open Hypermedia Systems, (Aarhus, Denmark, 2001), ACM.

10. Murray, J. Hamlet On The Holodeck: The Future of Narrative in Cyberspace. The Free Press, New York, 1997.

11. Trigg, R.H. and Weiser, M. "TEXTNET: A Network-Based Approach to Text Handling". ACM Transactions on Office Information Systems, 4 (1). 1-23.

12. Weal, M.J., Millard, D.E., Michaelides, D.T. and De Roure, D.C. Building Narrative Structures Using Context Based Linking. in Hypertext '01: Proceedings of the Twelfth ACM conference on Hypertext, (Aarhus, Denmark, 2001), ACM, 37-38. 